Nitric oxide contributes to copper tolerance by influencing ROS metabolism in Arabidopsis

Andrea Pető, Nóra Lehotai, Gábor Feigl, Nóra Tugyi, Attila Ördög, Katalin Gémes, Irma Tari, László Erdei \& Zsuzsanna Kolbert

\section{Plant Cell Reports}

ISSN 0721-7714

Plant Cell Rep

DOI 10.1007/s00299-013-1503-5

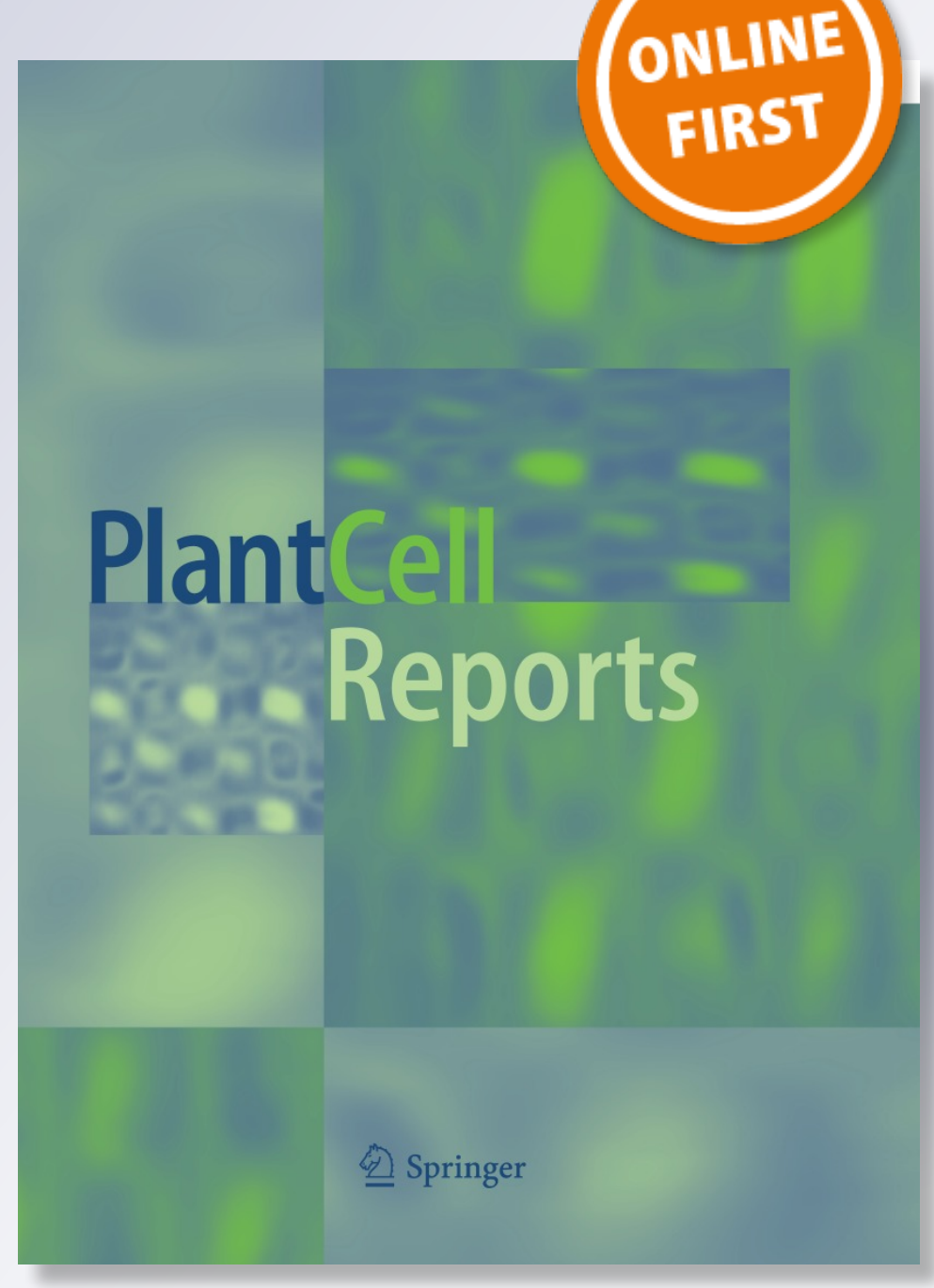

算 Springer 
Your article is protected by copyright and all rights are held exclusively by SpringerVerlag Berlin Heidelberg. This e-offprint is for personal use only and shall not be selfarchived in electronic repositories. If you wish to self-archive your article, please use the accepted manuscript version for posting on your own website. You may further deposit the accepted manuscript version in any repository, provided it is only made publicly available 12 months after official publication or later and provided acknowledgement is given to the original source of publication and a link is inserted to the published article on Springer's website. The link must be accompanied by the following text: "The final publication is available at link.springer.com". 


\title{
Nitric oxide contributes to copper tolerance by influencing ROS metabolism in Arabidopsis
}

\author{
Andrea Pető • Nóra Lehotai · Gábor Feigl • \\ Nóra Tugyi · Attila Ördög · Katalin Gémes • \\ Irma Tari $\cdot$ László Erdei $\cdot$ Zsuzsanna Kolbert
}

Received: 11 July 2013/ Accepted: 27 August 2013

(c) Springer-Verlag Berlin Heidelberg 2013

\begin{abstract}
Key message Nitric oxide improves copper tolerance via modulation of superoxide and hydrogen peroxide levels. This reflects the necessity of a well-coordinated interplay between NO and ROS during stress tolerance. Abstract Copper $(\mathrm{Cu})$ excess causes toxicity and one probable consequence of this is the disturbance of cell redox state maintenance, inter alia, by reactive oxygen(ROS) and nitrogen species (RNS). The objective of this paper was to examine the role of nitric oxide (NO) in $\mathrm{Cu}$ stress tolerance and its relationship with ROS in Arabidopsis. In agar-grown seedlings, concentration-dependent $\mathrm{Cu}$ accumulation was observed. The $5 \mu \mathrm{M} \mathrm{Cu}$ resulted in reduced cell viability in the NO overproducing noxl and gsnorl-3 root tips compared to the wild-type (WT). In contrast, 25 and $50 \mu \mathrm{M} \mathrm{Cu}$ caused higher viability in these mutants, while in the NO-lacking nialnia2 lower viability was detected than in the WT. The exogenous NO donor enhanced cell viability and scavenging endogenous NO decreased it in Cu-exposed WT seedlings. Besides, SNP in nialnia 2 roots led to the improvement of viability. The ascorbic acid-deficient mutants (vtc2-1, vtc2-3) possessing slightly elevated ROS levels proved to be $\mathrm{Cu}$ sensitive, while miox4 showing decreased ROS production was more tolerant to $\mathrm{Cu}$ than the WT. In noxl and gsnorl-3, $\mathrm{Cu}$ did not induce superoxide formation, and $\mathrm{H}_{2} \mathrm{O}_{2}$ accumulation occurred only in the case of NO deficiency. Based on these,
\end{abstract}

Communicated by Q. Zhao.

A. Pető · N. Lehotai · G. Feigl · N. Tugyi · A. Ördög ·

K. Gémes - I. Tari - L. Erdei · Z. Kolbert $(\bowtie)$

Department of Plant Biology, Faculty of Science and

Informatics, University of Szeged, Szeged, Hungary

e-mail: kolzsu@bio.u-szeged.hu under mild stress NO intensifies cell injury, while in the case of severe $\mathrm{Cu}$ excess it contributes to better viability. ROS were found to be responsible for aggravation of $\mathrm{Cu}$ induced damage. $\mathrm{NO}$ alleviates acute $\mathrm{Cu}$ stress via modulation of $\mathrm{O}_{2}^{--}$and $\mathrm{H}_{2} \mathrm{O}_{2}$ levels reflecting the necessity of a well-coordinated interplay between NO and ROS during stress tolerance.

Keywords Arabidopsis thaliana L. · Copper stress tolerance $\cdot$ Nitric oxide $\cdot$ Reactive oxygen species

\section{Introduction}

Copper $(\mathrm{Cu})$ is a vital trace element for normal root and shoot development; however, its excess can be toxic for most plants causing symptoms such as chlorosis and necrosis, stunting and serious growth inhibition (Reichman 2002). The reasons for $\mathrm{Cu}$ toxicity can be its binding to sulfhydryl groups in proteins, thus inhibiting protein functions, induction of nutrient deficiencies, impaired cell transport processes and disturbance in cell redox homeostasis (Yruela 2009). The redox status of plant cells is maintained by redox-active compounds (such as reactive oxygen- and nitrogen species and ascorbic acid), their oxidation/reduction states and interactions (Potters et al. 2010). Being a transition metal ion $\mathrm{Cu}$ catalyse, the Fenton and Haber-Weiss reactions, thereby directly inducing the production of different reactive oxygen species (ROS). The excessive amount of ROS is responsible for the damage to DNA, lipids and proteins, thus a tightly regulated ROS level is important for normal cell functions (Opdenakker et al. 2012). According to Opdenakker et al. (2012), hydrogen peroxide $\left(\mathrm{H}_{2} \mathrm{O}_{2}\right)$ can be produced by the dismutation of superoxide anion $\left(\mathrm{O}_{2}^{--}\right)$formed by NADPH 
oxidases or via the Fenton reactions in roots of $\mathrm{Cu}$-treated Arabidopsis. Besides, hydrogen peroxide can act as a signal molecule inducing OXI1-MAPK cascade leading to the regulation of gene expression or it can cause oxidative damage to the membrane lipids through the formation of the highly toxic hydroxyl radical $(\mathrm{OH} \cdot)$. Nitric oxide (NO) is a redox-active reactive nitrogen species (RNS) playing a role in normal plant development and also in stress acclimation processes. It has three redox forms (NO radical, nitrosonium cation and nitroxyl anion), which can be rapidly converted to each other in biological systems. Heavy metals, such as $\mathrm{Cu}$, influence NO levels in plant organs. In general, a short-term heavy metal treatment induces a rapid NO burst and a long treatment directly or indirectly decreases NO generation. Although it has to be mentioned that different heavy metal concentrations, duration of treatment and plant age also determine the effect of the metal on NO production (Xiong et al. 2010). Chemical properties of RNS enable them to act as a signal molecule in abiotic stress responses. For example, in favourable conditions, peroxynitrite can regulate cell signalling by the modification of lipids and/or proteins through tyrosine nitration or by interfering with phosphorylation cascades (Vandelle and Delledonne 2011). Reactive nitrogen species also induce the reversible posttranslational modification of thiol-containing proteins by $S$-nitrosylation leading to changes in enzyme activity during signalling processes (Astier et al. 2012). In fact, NO can have pro- or antioxidative effect during heavy metal stress depending on its actual concentration. The antioxidant activities of NO involve its ability to maintain the cellular redox balance and regulate ROS levels, thus controlling their toxicity. Nitric oxide is able to scavenge the superoxide anion in a chemical reaction leading to peroxynitrite $\left(\mathrm{ONOO}^{-}\right)$formation as it was observed in the roots of heavy metal-treated Lupinus luteus (Kopyra and Gwózdz 2003). This reaction is a key element of ROS and RNS interplay, which determines the different cell signalling pathways through the regulation of the steady-state levels of ROS and RNS (Molassiotis and Fotopoulos 2011). However, peroxynitrite is a strong oxidant in the animal systems, but it seems to be non-toxic for plant cells even at higher concentrations (Delledonne et al. 2001). Furthermore, NO is able to regulate superoxide production by the inhibition of NADPH oxidases via $S$-nitrosylation (Yun et al. 2011). Nitric oxide also induces the activity and expression of antioxidant enzymes such as $\mathrm{Cu} /$ zinc superoxide dismutase (Cu/Zn SOD), catalase (CAT), ascorbate peroxidase (APX), glutathione reductase (GR) and the metallothionein synthesis resulting decreased ROS production and alleviation of $\mathrm{Cu}$ toxicity (Hu et al. 2007; Wang et al. 2010).

The relationship between the reactive oxygen and nitrogen species in heavy metal stress tolerance has been investigated mainly using biochemical methods; therefore, in this study beyond the biochemical level the metabolism of reactive molecules was examined also genetically in the root system of $\mathrm{Cu}$-treated WT and mutant Arabidopsis thaliana seedlings.

\section{Materials and methods}

Plant material and growth conditions

During the experiments, seven-day-old wild-type (WT) and mutant Arabidopsis thaliana L. seedlings were used. Noxl (cuel) is an NO overproducing mutant having higher L-arginine, L-citrulline and NO contents as compared to the WT. CUE1 is the chlorophyll a/b binding protein under expressed 1 gene that encodes the phosphoenolpyruvate/phosphate translocator in the plastid inner envelope (He et al. 2004). The $S$-nitrosoglutathione reductase (GSNOR) activity of gsnorl-3 Arabidopsis plants is reduced by $80 \%$ compared to WT and this mutant has higher total $S$-nitrosothiol, nitrate and NO levels (Feechan et al. 2005; Rustérucci et al. 2007; Lee et al. 2008). In Arabidopsis, nitrate reductase enzyme is encoded by the NIA1 and NIA2 genes. The nialnia2 is a nitrate reductase-deficient mutant, with a point mutation in NIA1 and a deletion in NIA2 gene, having only $0.5 \%$ of the NR enzyme activity of the WT (Wilkinson and Crawford 1993). The mutant also possesses lower arginine and nitrite levels (Modolo et al. 2006). Arabidopsis plants with low (vtc2-1 and vtc 2-3) or high (miox4) ascorbic acid contents were also used. The $v t c 2-1$ plants contain 25-30\% of WT ascorbic acid (Conklin et al. 2000) and $v t c 2-3$ shows $40-50 \%$ of the WT AsA level (Conklin 2001). The myo-inositol oxygenase (MIOX4) gene is overexpressed in miox4 transgenic Arabidopsis resulting 2-3fold ascorbic acid accumulation in the leaves (Lorence et al. 2004). All Arabidopsis lines were of the ecotype Columbia (Col) background. The seeds of all plant lines were surface sterilised with $5 \%(\mathrm{v} / \mathrm{v})$ sodium hypochlorite and transferred to half-strength Murashige and Skoog medium (1\% (w/v) sucrose and $0.8 \%(\mathrm{w} / \mathrm{v})$ agar) supplemented with $0,5,25$ or $50 \mu \mathrm{M} \mathrm{CuSO}_{4}$. The Petri dishes were kept in a greenhouse at a photo flux density of $150 \mu \mathrm{mol} \mathrm{m}{ }^{-2} \mathrm{~s}^{-1}(12 / 12$ day/night period) at a relative humidity of $55-60 \%$ and $25 \pm 2{ }^{\circ} \mathrm{C}$. As an NO scavenger, $\quad 50 \mu \mathrm{M}$ 2-(4-carboxyphenyl)-4,4,5,5-tetramethylimidazoline-1-oxyl-3-oxid potassium salt (cPTIO) was used. Also, sodium nitroprusside (SNP) as an NO donor was applied at a concentration of $10 \mu \mathrm{M}$. These chemicals were added to the nutrient media before the seeds were planted. 
Element analysis by inductively coupled plasma mass spectrometry (ICP-MS)

Fourteen-day-old WT Arabidopsis plants were exposed to different $\mathrm{Cu}$ concentrations $\left(0,5,25\right.$ and $\left.50 \mu \mathrm{M} \mathrm{CuSO}_{4}\right)$, then roots and shoots were separated and washed with distilled water. Approximately 1,000 seedlings were used for a treatment; each measurement was repeated twice. After drying $\left(70{ }^{\circ} \mathrm{C}, 72 \mathrm{~h}\right)$, nitric acid $\left[\mathrm{HNO}_{3}, 65 \%\right.$ (w/v)] and hydrogen peroxide $\left[\mathrm{H}_{2} \mathrm{O}_{2}, 30 \%(\mathrm{w} / \mathrm{v})\right]$ were added to the dry material and the samples were destructed by microwave-assisted digestion (MarsXpress CEM, Matthews, USA) at $200{ }^{\circ} \mathrm{C}$ on $1,600 \mathrm{~W}$ for $15 \mathrm{~min}$. The samples were cooled and diluted with distilled water and the element analysis was carried out by ICP-MS (Thermo Scientific XSeries II, Asheville, USA). Values of $\mathrm{Cu}$ and other microelement ( $\mathrm{Fe}, \mathrm{Zn}, \mathrm{Mn}, \mathrm{Mo}, \mathrm{B})$ concentrations are given in $\mu \mathrm{g} \mathrm{g}^{-1}$ dry weight (DW) and from the data shoot to root ratio was calculated.

\section{Morphological observations}

Seedling morphology of WT and mutant Arabidopsis was observed under Zeiss Axioskope 200-C stereomicroscope (Carl Zeiss, Jena, Germany). Fresh weights (FW) of the whole plants were measured using a balance and were expressed as average weight of ten seedlings.

\section{Fluorescence microscopy}

Nitric oxide levels in Arabidopsis roots were analysed by 4-amino-5-methylamino-2', $7^{\prime}$-difluorofluorescein diacetate (DAF-FM DA) according to Pető et al. (2011). Whole seedlings were incubated for $30 \mathrm{~min}$ in $10 \mu \mathrm{M}$ dye solution (prepared in $10 \mathrm{mM}$ Tris- $\mathrm{HCl}, \mathrm{pH}$ 7.4) and were washed twice within $30 \mathrm{~min}$ with Tris-HCl. Dihydroethidium (DHE, $10 \mu \mathrm{M}$ ) in Tris-HCl buffer was used to visualise superoxide radical in Arabidopsis plants (Lehotai et al. 2011). To detect total intracellular ROS, $10 \mu \mathrm{M} 2^{\prime}-7^{\prime}$ dichlorodihydrofluorescein diacetate $\left(\mathrm{H}_{2}\right.$ DCF-DA) was used at $37^{\circ} \mathrm{C}$ for $15 \mathrm{~min}$, then the samples were washed four times in 20 min with 2-N-morpholine-ethansulphonic acid/potassium chloride $\mathrm{MES} / \mathrm{KCl}\left(10^{-3} \mathrm{M}, \mathrm{pH}\right.$ 6.15) buffer. For in situ $\mathrm{H}_{2} \mathrm{O}_{2}$ detection, 10-acetyl-3,7-dihydroxyphenoxazine (ADHP or Ampiflu ${ }^{\mathrm{TM}}$ ) fluorescent dye was used. Seedlings were incubated in small Petri dishes with $2 \mathrm{ml}$ of $50 \mu \mathrm{M}$ ADHP dye solution (prepared in $50 \mathrm{mM}$ sodium phosphate buffer, $\mathrm{pH} 7.5$ ) for $30 \mathrm{~min}$ and washed once with the buffer (Lehotai et al. 2012). Fluorescein diacetate (FDA) was used for the determination of cell viability according to Lehotai et al. (2011). Investigations were carried out using a Zeiss Axiowert 200M-type inverted-fluorescence microscope (Carl Zeiss, Jena,
Germany) equipped with a high resolution digital camera (Axiocam HR, HQ CCD) with filter set 10 (excitation 450-490 nm, emission: $515-565 \mathrm{~nm}$ ), filter set 20HE (excitation: $535-585 \mathrm{~nm}$, emission: $600-655 \mathrm{~nm}$ ) and filter set 9 (excitation: $450-490 \mathrm{~nm}$; emission: $515-\infty \mathrm{nm}$ ). Fluorescence intensities (pixel intensity) were measured on digital images within circular areas of $45 \mu \mathrm{m}$ radii using Axiovision Rel. 4.8 software. The radii of circles were not modified during the experiments.

\section{Statistical analysis}

Results are expressed as mean \pm SE. Multiple comparison analyses were performed with SigmaStat 11 software using analysis of variance (ANOVA, $P<0.05$ ) and Duncan's test. In some cases, Microsoft Excel 2010 and Student's $t$ test were used $(* P \leq 0.05, * * P \leq 0.01, * * * P \leq 0.001)$. All experiments were carried out at least two times. In each treatment, at least 10 samples were measured.

\section{Results}

Copper uptake, translocation and microelement homeostasis in WT Arabidopsis

Microelement concentrations of control, 5, 25 and $50 \mu \mathrm{M}$ Cu-treated WT Arabidopsis plants were measured by ICPMS and shoot to root ratio was calculated to draw conclusions about element distribution. In control plants, the root showed higher $\mathrm{Cu}$ concentrations than the shoot, however; as the effect of the metal treatment the $\mathrm{Cu}$ accumulation was more significant within the shoot system. Decreased iron content was observed in the shoots of the treated plants, since the concentration of this microelement in the root was significantly enhanced, thus the shoot to root ratio was modified by $\mathrm{Cu}$. Zinc homeostasis of the roots was also affected by $\mathrm{Cu}$ excess, because reduced concentrations were measured compared to the control leading to significant increase of shoot to root ratio. Mild $\mathrm{Cu}$ stress $(5 \mu \mathrm{M})$ resulted in an increase of manganese and molybdenum contents within the root system. The concentration of the latter element in the shoot was decreased, thus the distribution of it altered within the $\mathrm{Cu}$-exposed seedlings compared to non-treated plants. Moreover, $\mathrm{Cu}$ treatment led to the reduction of boron content in both organs (Table 1).

Different growth and copper sensitivity of nitric oxide(nox1, gsnor1-3, nialnia2) and ascorbic acid (vtc2-1, vtc2-3, miox4) mutant Arabidopsis

First, the NO, $\mathrm{H}_{2} \mathrm{O}_{2}$ and total, intracellular ROS levels were detected in the primary root tips of the mutant 
Table 1 Microelement concentrations $\left(\mu \mathrm{g} \mathrm{g}^{-1} \mathrm{DW}\right)$ and shoot: root ratios of $0,5,25$ and $50 \mu \mathrm{M}$ copper-treated Arabidopsis

\begin{tabular}{|c|c|c|c|c|c|c|c|}
\hline \multirow[t]{2}{*}{$\mathrm{CuSO}_{4}$} & \multicolumn{7}{|l|}{ Shoot } \\
\hline & $0 \mu \mathrm{M}$ & $5 \mu \mathrm{M}$ & & $25 \mu \mathrm{M}$ & & $50 \mu \mathrm{M}$ & \\
\hline $\mathrm{Cu}$ & $17.39 \pm 0.43$ & $82.23 \pm 0.70$ & $* * *$ & $234.50 \pm 1.96$ & $* * *$ & $514.20 \pm 1.27$ & $* * *$ \\
\hline $\mathrm{Fe}$ & $628.70 \pm 3.31$ & $438.60 \pm 1.43$ & $* * *$ & $494.60 \pm 3.20$ & $* * *$ & $431.20 \pm 2.35$ & **** \\
\hline $\mathrm{Zn}$ & $204.00 \pm 5.05$ & $169.80 \pm 0.95$ & ** & $168.50 \pm 1.36$ & ** & $196.60 \pm 0.45$ & n.s. \\
\hline $\mathrm{Mn}$ & $129.20 \pm 0.26$ & $136.90 \pm 0.35$ & $* * *$ & $113.90 \pm 0.60$ & $* * *$ & $120.20 \pm 0.11$ & *** \\
\hline Mo & $12.91 \pm 0.02$ & $9.68 \pm 0.03$ & $* * *$ & $9.60 \pm 0.01$ & $* * *$ & $7.56 \pm 0.04$ & $* * *$ \\
\hline B & $80.31 \pm 0.15$ & $66.20 \pm 0.58$ & $* * *$ & $40.19 \pm 0.32$ & $* * *$ & $55.87 \pm 0.36$ & *** \\
\hline \multirow[t]{2}{*}{$\mathrm{CuSO}_{4}$} & \multicolumn{7}{|l|}{ Root } \\
\hline & $0 \mu \mathrm{M}$ & $5 \mu \mathrm{M}$ & & $25 \mu \mathrm{M}$ & & $50 \mu \mathrm{M}$ & \\
\hline $\mathrm{Cu}$ & $26.14 \pm 0.54$ & $78.93 \pm 0.91$ & $* * *$ & $194.10 \pm 16.51$ & $* * *$ & $280.81 \pm 5.99$ & *** \\
\hline $\mathrm{Fe}$ & $1860.00 \pm 6.52$ & $2151.00 \pm 18.99$ & $* * *$ & $3409.00 \pm 10.55$ & $* * *$ & $2692.02 \pm 9.41$ & **** \\
\hline $\mathrm{Zn}$ & $269.30 \pm 1.31$ & $144.00 \pm 0.88$ & $* * *$ & $121.50 \pm 0.07$ & $* * *$ & $160.10 \pm 0.89$ & *** \\
\hline Mn & $146.40 \pm 0.94$ & $173.10 \pm 0.66$ & $* * *$ & $124.53 \pm 0.94$ & $* * *$ & $129.50 \pm 0.24$ & $* * *$ \\
\hline Mo & $13.71 \pm 0.04$ & $16.92 \pm 0.04$ & $* * *$ & $14.78 \pm 0.10$ & $* * *$ & $13.86 \pm 0.09$ & n.s. \\
\hline B & $123.92 \pm 0.89$ & $79.95 \pm 0.69$ & $* * *$ & $25.82 \pm 0.39$ & $* * *$ & $71.87 \pm 1.18$ & *** \\
\hline \multirow[t]{2}{*}{$\mathrm{CuSO}_{4}$} & \multicolumn{7}{|l|}{ Shoot:Root } \\
\hline & $0 \mu \mathrm{M}$ & $5 \mu \mathrm{M}$ & & $25 \mu \mathrm{M}$ & & $50 \mu \mathrm{M}$ & \\
\hline $\mathrm{Cu}$ & 0.665 & 1.041 & $* * *$ & 1.208 & $* *$ & 1.831 & **** \\
\hline $\mathrm{Fe}$ & 0.338 & 0.203 & $* * *$ & 0.145 & $* * *$ & 0.160 & *** \\
\hline $\mathrm{Zn}$ & 0.757 & 1.179 & $* * *$ & 1.386 & $* * *$ & 1.227 & *** \\
\hline $\mathrm{Mn}$ & 0.882 & 0.790 & $* * *$ & 0.914 & $* * *$ & 0.928 & $* *$ \\
\hline Mo & 0.942 & 0.572 & $* * *$ & 0.649 & *** & 0.545 & **** \\
\hline B & 0.648 & 0.828 & $* * *$ & 1.557 & $* * *$ & 0.777 & $* *$ \\
\hline
\end{tabular}

The lack of significancy (n.s.) or significant differences according to Student's $t$-test $(n=10, * P \leq 0.05, * * P \leq 0.01, * * * P \leq 0.001)$ are indicated

Microelement concentration $\left(\mu \mathrm{g} \mathrm{g}^{-1} \pm \mathrm{SE}\right)$

Arabidopsis seedlings. In noxl and gsnorl-3 plants, approximately twofold NO accumulation was found compared to the WT and the nitrate reductase-deficient nialnia2 roots showed only $\sim 40 \%$ of the NO level of the WT (Table $2 \mathrm{a}$ ). In the primary root tips of the ascorbic aciddeficient vtc2-1 mutant, slightly but not significantly elevated $\mathrm{H}_{2} \mathrm{O}_{2}$ and total $\mathrm{ROS}$ levels were observed, while $v t c 2-3$ roots showed more pronounced ROS accumulation. In contrast, slightly reduced $\mathrm{H}_{2} \mathrm{O}_{2}$ and total ROS-dependent fluorescence were detected in miox4 mutants (Table 2b).

During control conditions, NO overproducer and deficient mutants showed reduced cotyledon and root sizes as compared to WT. In contrast, the shoot and root sizes of the non-stressed $v t c 2-1, v t c 2-3$ and miox 4 were similar to Col-0 (Fig. 1a). Unlike the WT, fresh weight of the NO overproducer plants slightly increased as an effect of mild $\mathrm{Cu}$ stress $(5 \mu \mathrm{M} \mathrm{CuSO} 4)$. More serious metal excess caused growth inhibition and decrease of fresh weight in noxl and gsnor 1-3 mutants to a similar extent as in the WT. In $50 \mu \mathrm{M} \mathrm{Cu}$-treated nialnia2 plants, the loss of fresh weight was more pronounced than in Col-0. In the case of the two vtc mutants, low $\mathrm{Cu}$ concentrations led to a slight increase in FW, while more serious metal excess caused fresh weight loss similar to that in the WT. The fresh weight diminution of the myo-inositol oxygenase overexpressing plants (miox4) was similar to that of Col-0, but proved to be milder than in the NO-deficient nialnia2 (Fig. 1b). In root meristem cells of WT plants, only $50 \mu \mathrm{M} \mathrm{Cu}$ caused significant loss of viability, while in the NO overproducing noxl mutant, the lowest concentration reduced and the more serious $\mathrm{Cu}$ excess only slightly decreased cell viability. In gsnor 1-3 roots, similar tendency was observed, since higher $\mathrm{Cu}$ concentrations did not affect cell viability. More pronounced $\mathrm{Cu}$ sensitivity was observed in nialnia2 plants, because all the applied concentrations triggered loss of viability in the root apex (Fig. 1c). In primary root tips of the AsA-deficient $v t c 2-1$ and $v t c 2-3,25$ and $50 \mu \mathrm{M} \mathrm{Cu}$ 
Table 2 (a) Nitric oxide levels (pixel intensities of DAF-FM fluorescence) in the primary root tips of untreated WT, noxl, gsnorl-3 and nialnia2 Arabidopsis seedlings. (b) $\mathrm{H}_{2} \mathrm{O}_{2}$ and total $\mathrm{ROS}$ levels (pixel intensities of resorufin and DCF fluorescence) in the primary root tips of untreated WT, vtc2-1, vtc2-3 and miox4 seedlings

\begin{tabular}{lclcr}
\hline (a) & NO $($ WT \%) & (b) & $\mathrm{H}_{2} \mathrm{O}_{2}(\mathrm{WT} \%)$ & Total ROS (WT \%) \\
\hline WT & $100 \pm 3.04$ & WT & $100 \pm 6.97$ & $100 \pm 6.17$ \\
nox1 & $215.70 \pm 2.15^{* * *}$ & $v t c 2-1$ & $111.64 \pm 8.09$ n.s. & $119.07 \pm 12.49$ n.s. \\
gsnorl-3 & $170.20 \pm 2.32^{* * *}$ & vtc2-3 & $133.87 \pm 6.73 *$ & $138.20 \pm 9.03$ n.s. \\
nialnia2 & $39.45 \pm 0.99 * * *$ & miox4 & $90.17 \pm 3.83$ n.s. & $90.69 \pm 13.64$ n.s.
\end{tabular}

The data are expressed as percentage of the wild-type. The lack of significancy (n.s.) or significant differences according to Student's $t$-test $(n=10, * P \leq 0.05, * * P \leq 0.01, * * * P \leq 0.001)$ are indicated

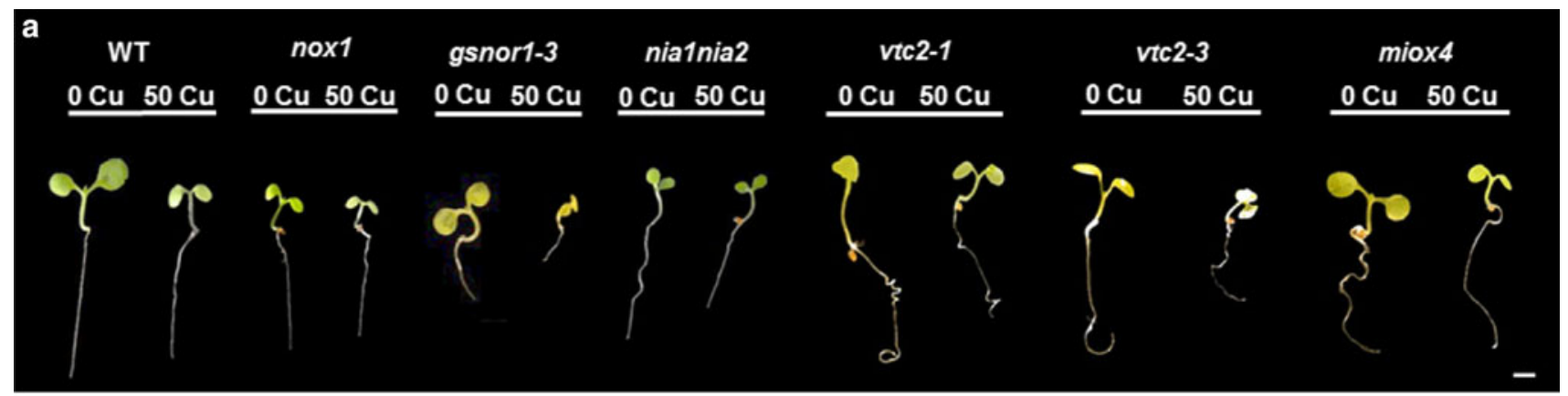

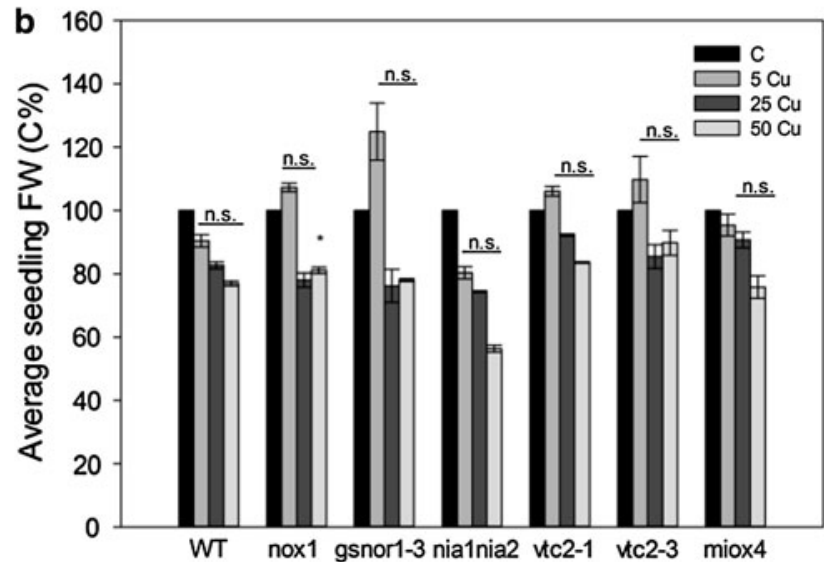

Fig. 1 a Representative stereomicroscopic images of seven-day-old WT and mutant Arabidopsis seedlings treated with 0 or 50. Bar $1 \mathrm{~mm}$ b Average fresh weight (control \%) of WT, nox1, gsnorl-3, nialnia2, $v t c 2-1, v t c 2-3$ and miox4 seedlings treated with $0,5,25$ and $50 \mu \mathrm{M}$

significantly decreased cell viability. $\mathrm{Cu}$ excess did not reduce the viability of miox4 plants having lower ROS levels; moreover, low metal excess resulted in enhanced viability (Fig. 1c).

Copper tolerance is associated with altered nitric oxide levels in the roots

The basal NO content of the WT and mutant roots was biochemically modified by NO donor (SNP) and/or scavenger (cPTIO) treatment to determine whether, $\mathrm{Cu}$ tolerance or sensitivity is associated with NO levels. Exogenous

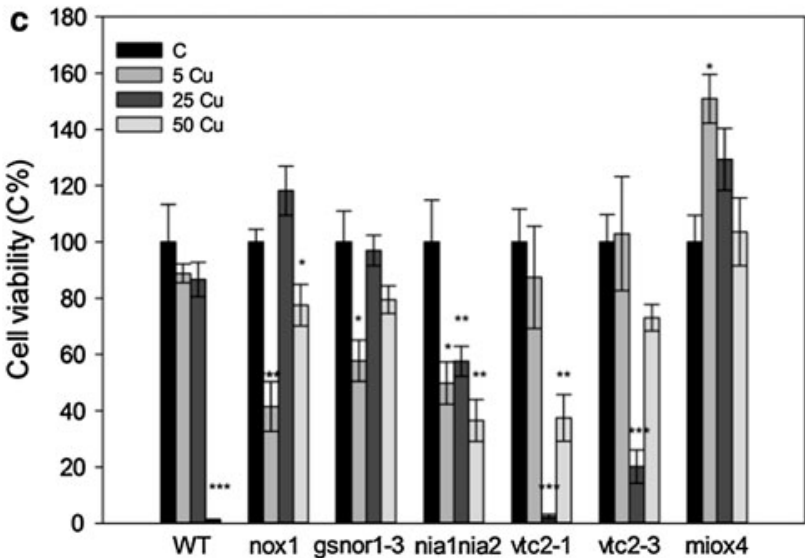

$\mathrm{Cu}$. c Cell viability in root meristem of control and $\mathrm{Cu}$-treated WT, NO and ascorbic acid mutant Arabidopsis. The lack of significancy (n.s.) or significant differences according to Student's $t$-test $(n=10$, $* P \leq 0.05, * * P \leq 0.01, * * * P \leq 0.001)$ are indicated

NO prevented WT root tips from Cu-induced viability loss, while treatment with the NO scavenger resulted in decreased viability (Fig. 2a). Quenching of NO in noxl mutant resulted in higher cell viability, especially in the 5 and $50 \mu \mathrm{M} \mathrm{Cu}$-treated roots (Fig. 2b). In the gsnorl-3 mutants treated with $50 \mu \mathrm{M} \mathrm{Cu}$ plus cPTIO showed elevated viability compared to those treated with $\mathrm{Cu}$ alone. However, the notable viability loss in $5 \mu \mathrm{M}$ Cu-treated roots was not ameliorated by reducing $\mathrm{NO}$ levels of gsnorl-3 (Fig. 2c). When the low NO content of the $\mathrm{Cu}$ treated nialnia2 mutants was enhanced by SNP addition, cell viability of root meristem increased (Fig. 2d). 

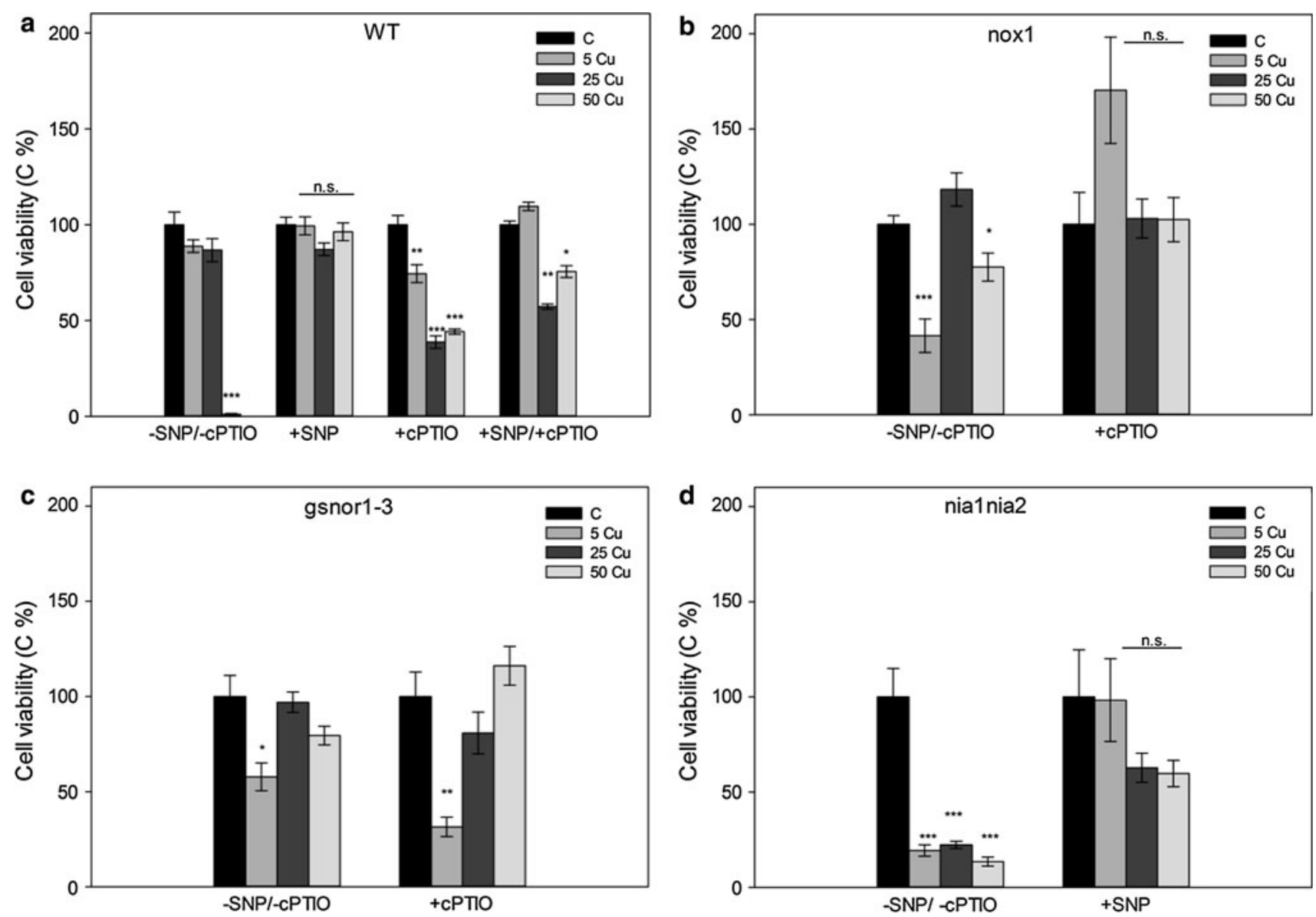

Fig. 2 a-d Cell viability in root tips of WT, nox1, gsnor1-3 and nialnia2 Arabidopsis treated with different copper concentrations without $(-\mathrm{SNP} /-\mathrm{cPTIO})$ or with $10 \mu \mathrm{M} \mathrm{SNP}(+\mathrm{SNP})$ or $50 \mu \mathrm{M}$ cPTIO $(+$ cPTIO) or with SNP and cPTIO together $(+\mathrm{SNP} /+$ cPTIO $)$.

Interplay between NO and ROS during copper stress in Arabidopsis roots

To explore a possible relationship between ROS and NO metabolism during $\mathrm{Cu}$ stress, the levels of different ROS forms (superoxide radical and hydrogen peroxide) were studied in NO overproducing and deficient mutants and vice versa. Superoxide levels in control root tips were lower in mutants having elevated NO contents (noxl, gsnorl-3) and were higher in the NO-deficient nialnia2. As an effect of $\mathrm{Cu}$ exposure, superoxide levels increased in WT Arabidopsis roots; however, they decreased in the NO overproducing noxl and the deficient nialnia2 mutants. Besides, in gsnorl-3 roots, a non-significant $\mathrm{O}_{2}^{-}$depletion was detected (Fig. 3a, c). A consequent $\mathrm{Cu}$-induced $\mathrm{H}_{2} \mathrm{O}_{2}$ accumulation was observed only in the case of the NO deficient nialnia2 Arabidopsis. In the WT and NO overproducing plants, $\mathrm{H}_{2} \mathrm{O}_{2}$ decreased as an effect of $\mathrm{Cu}$ treatment (Fig. 3b, c). In non-treated AsA mutants, significantly reduced NO levels were measured compared to

The lack of significancy (n.s.) or significant differences according to Student's $t$-test $(n=10, * P \leq 0.05, * * P \leq 0.01, * * * P \leq 0.001)$ are indicated

the WT; however, the mutants possessing reduced or elevated ROS levels, did not significantly differ from each other. The effect of $\mathrm{Cu}$ on NO metabolism did not prove to be significant in the mutants showing altered ascorbate levels (Fig. 3d).

\section{Discussion}

Copper uptake, translocation and microelement homeostasis in wild-type Arabidopsis

Concentrations of microelements ( $\mathrm{Cu}, \mathrm{Fe}, \mathrm{Zn}, \mathrm{Mn}, \mathrm{Mo}, \mathrm{B})$ in the shoot and root system and their organismal-level distributions were determined in Arabidopsis grown on nutrient agar medium (Table 1). Based on the results, Arabidopsis seedlings are able to uptake and accumulate a portion of the $\mathrm{Cu}$ and translocate it into the shoot system. Presumably, $\mathrm{Cu}$ makes complexes with nicotianamine and is transported via xylem vessels into the shoot system 

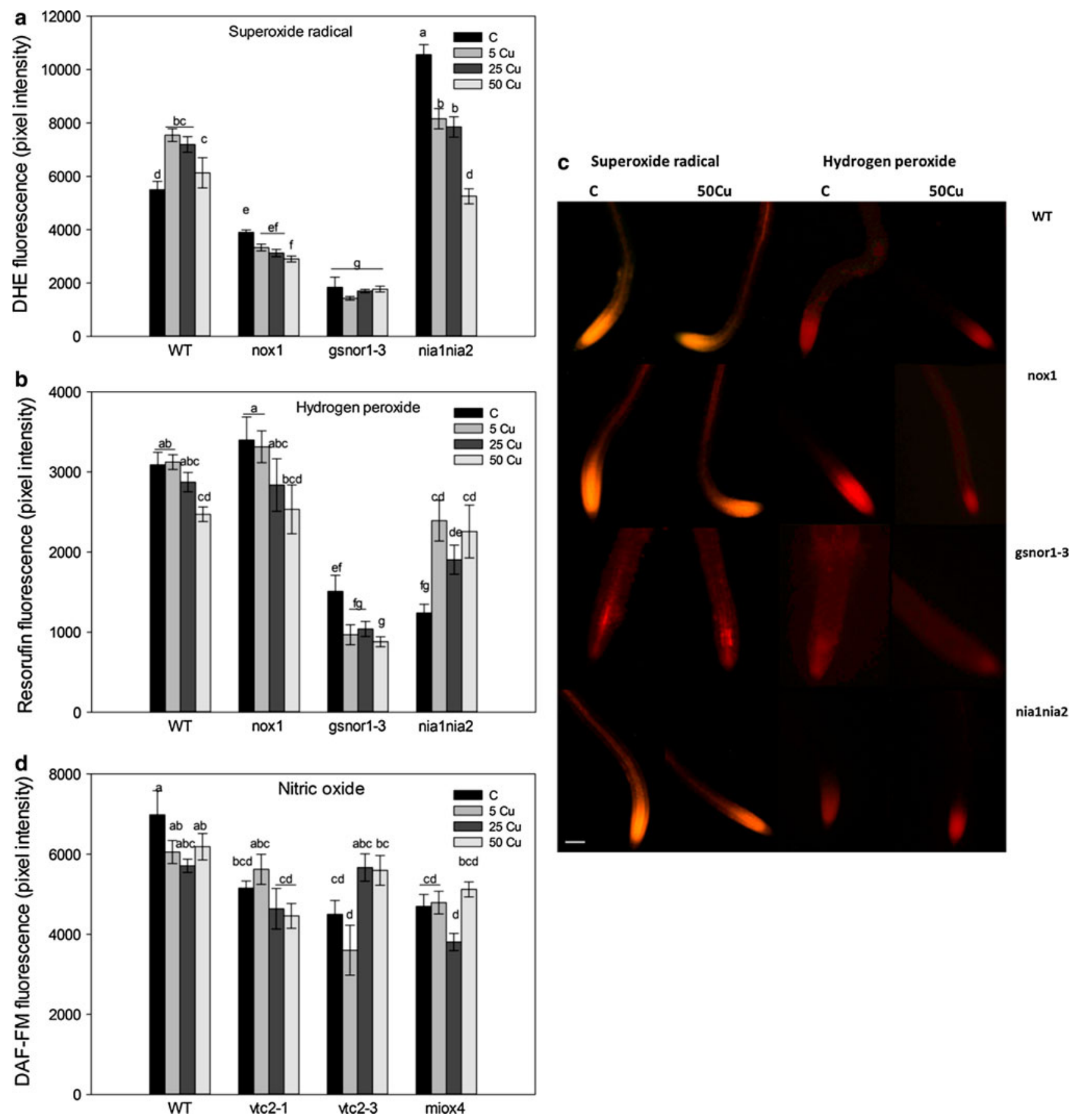

Fig. 3 Superoxide (pixel intensities of DHE fluorescence, a and $\mathrm{H}_{2} \mathrm{O}_{2}$ (pixel intensities of resorufin fluorescence, $\mathbf{b}$ levels in WT and NO mutant Arabidopsis. c Representative images of control and $50 \mu \mathrm{M}$ copper-treated WT and mutant Arabidopsis root tips stained by DHE or Ampiflu ${ }^{\mathrm{TM}}$, respectively. Bar $100 \mu \mathrm{m}$. Nitric oxide levels

(Burkhead et al. 2009). Cu excess notably modifies microelement homeostasis of the seedlings. The reduced shoot iron content reflects the antagonism between $\mathrm{Cu}$ and Fe due to their competition during the uptake (Lequeux et al. 2010). The main symptom of iron deficiency is intervenial chlorosis (Taylor and Foy 1985), which was

(pixel intensities of DAF-FM fluorescence, $\mathbf{d}$ in root meristems of WT and ascorbic acid mutant Arabidopsis treated with 0, 5, 25 and $50 \mu \mathrm{M}$ copper. Different letters indicate significant differences according to Duncan-test $(n=10, P \leq 0.05)$

clearly visible in the cotyledons of Arabidopsis seedlings (see Fig. 2a). Elevated iron concentrations in the roots of $\mathrm{Cu}$-treated plants could be explained by the fact that $\mathrm{Cu}$ is able to intensify iron availability by displacing it from FeEDTA complexes in the nutrient medium (Lequeux et al. 2010). Root zinc status was negatively affected by $\mathrm{Cu}$ 
excess, since both ions use the same transporter molecules, ZINC-REGULATED TRANSPORTERS, IRON-REGULATED TRANSPORTER-LIKE PROTEINS (ZIP, Wintz et al. 2003). The reducing effect of $\mathrm{Cu}$ on manganese, molybdenum and boron contents can be explained by the fact that $\mathrm{Cu}$ may change their uptake rates (Lidon and Henriques 1993). In general, $\mathrm{Cu}$ exposure significantly modified the shoot-root distribution of the examined microelements within the seedlings. The serious disturbances of microelement homeostasis can result in growth inhibition of $\mathrm{Cu}$-exposed Arabidopsis seedlings.

Different growth and copper sensitivity of nitric oxide(nox1, gsnor1-3, nialnia2) and ascorbic acid (vtc2-1, vtc2-3, miox4) mutant Arabidopsis

First and foremost, the NO and ROS levels were verified in the root tips of the mutants to justify the effect of the mutations on the production of these molecules (Table 2). In the root tip of noxl, enhanced NO levels were detected due to the probable oxidative NO synthesis following from elevated L-arginine concentration in this mutant (He et al. 2004). The gsnorl-3 plants are defective in NO removal mediated by GSNO reductase (Feechan et al. 2005), which results in highly elevated (170\% of the WT) NO levels. The nitrate reductase-deficient nialnia2 double mutant showed significantly reduced NO levels compared to the WT, which suggests the involvement of this enzyme in NO synthesis of non-stressed Arabidopsis roots. Similarly, decreased NO level was published in nialnia2 roots by Lozano-Juste and Léon (2010). Interestingly, the vtc2-3 mutant containing higher (40-50\% of the WT) AsA concentration than vtc2-1 (Conklin 2001) showed more pronounced enhancement of $\mathrm{H}_{2} \mathrm{O}_{2}$ (and total ROS), although the difference showed only a low level of significance. Similarly, slight differences in hydrogen peroxide concentrations were measured in whole seedlings of $v t c$ mutants (Barth et al. 2010). In contrast, the miox4 roots possessing elevated ascorbic acid contents showed reduced levels of $\mathrm{H}_{2} \mathrm{O}_{2}$ and total intracellular ROS. Considering the statistically non-significant differences, it can be concluded that ascorbic acid participates in the regulation of ROS levels in non-stressed Arabidopsis roots; however, other elements of the antioxidant system (e.g. glutathione and enzymes) can also be involved in this process. The mutant seedlings possessing altered NO metabolism (noxl, gsnorl-3 and nialnia2) showed reduced shoot and root sizes and fresh weights as compared to the WT, suggesting the necessity of an optimal NO level for the appropriate growth (Fig. 1). Moreover, the semidwarf phenotype of gsnorl-3 reflects that the GSNOR-dependent NO removal is necessary for the optimal development (Lee et al. 2008). The results are supported by the work of He et al. (2004), where high NO level (exogenous sodium nitroprusside treatment) resulted in growth inhibition of Arabidopsis and an optimal SNP concentration for promoting shoot growth was determined. Furthermore, contrasting effects were observed also in pea leaves depending on the actual tissue concentration of NO (Leshem and Haramaty 1996). Also in the root system, the growth inducing effect of NO is dosedependent, since higher levels of exogenously applied NO (as chemical NO donor) caused growth inhibition (Gouvêa et al. 1997; Pagnussat et al. 2002). In accordance with the results of Dowdle et al. (2007), vtc2-3 showed WT-like shoot and root size under control conditions. Also, nonstressed miox 4 plants had a size similar to WT. These results are similar to those of Alford (2009), where WTlike hypocotyl and root length of miox4 was measured during control circumstances. These suggest that modified ascorbate contents and consequently slightly altered ROS levels do not significantly influence the early development of Arabidopsis seedlings. According to Epstein and Bloom (2005) basal $\mathrm{Cu}$ levels in plants ranged from 2 to $50 \mu \mathrm{g} \mathrm{g}^{-1} \mathrm{DW}$, and in agar medium $\mathrm{Cu}$ concentrations above $20 \mu \mathrm{M}(1.27 \mathrm{ppm})$ is considered to be toxic (Murphy and Taiz 1995). Based on these, the lowest $\mathrm{CuSO}_{4}$ concentration $(5 \mu \mathrm{M})$ applied in this study resulted in slightly elevated $\mathrm{Cu}$ level $\left(\sim 80 \mu \mathrm{g} \mathrm{g}^{-1} \mathrm{DW}\right.$, see Table 1$)$ and it proved to be not toxic for Col-0 seedlings. What is more, $5 \mu \mathrm{M} \mathrm{Cu}$ treatment had a slight growth promoting effect (non-significant elevation of FW), though elevated $\mathrm{NO}$ and ROS levels were needed for this. In the case of NO deficiency, $\mathrm{Cu}$ had a more pronounced growth-reducing effect than in the WT, reflecting the role of this molecule in the maintenance of growth under abiotic stress conditions. In the same experimental setup, the nialnia2 seedlings showed serious $\mathrm{Cu}$-induced reduction in cell elongation during hypocotyl and primary root growth (Petö et al. 2011).

Copper sensitivity was evaluated by studying the viability of root meristem cells using fluorescent microscopy. During mild stress, high NO levels intensified sensitivity, while under severe stress conditions they facilitated tolerance. This means that the role of NO signalling depends on the strength of the stress. Under mild $\mathrm{Cu}$ stress, the negative effect on viability can be reversible by scavenging the high NO level in noxl (see Fig. 2b). The assent of NO to abiotic or biotic stress tolerance was evidenced by several authors. For instance, the high $S$-nitrosothiol level of gsnorl-3 was shown to be an important contributor to thermo- or selenite tolerance (Lee et al. 2008; Lehotai et al. 2012) and the NO-deficient nialnia2 mutant proved to be less tolerant to other stressors such as water deficit, freezing or selenite excess (Zhao et al. 2009; Lozano-Juste and Léon 2010; Lehotai et al. 2012). Recently, an NO-overproducing tomato mutant $(s h r)$ was isolated, in which the 
disease resistance was associated with the enhanced NO production (Negi et al. 2010). Based on the reduced viability in $\mathrm{Cu}$-exposed vtc2-1, vtc $2-3$ and the more viable cells in miox 4 roots, enhanced ROS content due to reduced AsA level triggers $\mathrm{Cu}$ sensitivity, while decreased ROS concentration as a result of AsA overproduction favours $\mathrm{Cu}$ tolerance. Elevated ROS levels induce disturbances in redox state leading to oxidative damage to the cells (Potters et al. 2010), which is likely to intensify $\mathrm{Cu}$ sensitivity. The $v t c 2$ mutants proved to be more susceptible to other environmental stresses such as heat, salt, photooxidative stress and selenite excess (Smirnoff 2000; Müller-Moulé et al. 2004; Larkindale et al. 2005; Lehotai et al. 2012).

Copper tolerance is associated with altered nitric oxide levels in the roots

During biochemical studies, exogenous NO donor (SNP) and scavenger (cPTIO) treatments were applied to verify the involvement of $\mathrm{NO}$ in the development of $\mathrm{Cu}$ tolerance. Based on the higher viability of NO-treated WT plants, NO ameliorated cell injury induced by severe $\mathrm{Cu}$ excess (Fig. 2). The increased $\mathrm{Cu}$ tolerance of the NO overproducing mutants and the more pronounced sensitivity of nialnia2 Arabidopsis also confirm the stress mitigating effect of NO (see Fig. 1). Similar results were obtained by Cui et al. (2010), where NO treatment reduced lipid peroxidation and increased the root fresh weight in $\mathrm{Cu}$-treated tomato plants. In another study, Panax ginseng plants treated with SNP and subsequently exposed to $\mathrm{Cu}$ exhibited a significantly reduced cell death and oxidative damage to the membranes (Tewari et al. 2008). However, the results also show that $\mathrm{Cu}$ resistance determined by root cell viability is associated with a strictly regulated NO balance, since higher or lower than the optimal NO level may result in cell damage (Fig. 2b, c).

\section{Interplay between NO and ROS during copper stress in Arabidopsis roots}

The possible connection between $\mathrm{NO}$ and ROS during $\mathrm{Cu}$ stress was also examined using microscopic methods. Elevated NO level resulted in reduced superoxide contents of the control Arabidopsis root tips and vice versa. It follows that under stress-free conditions, NO is able to negatively regulate superoxide levels possibly by the chemical reaction yielding peroxynitrite formation (Koppenol et al. 1992) or by modifying the activities of antioxidants such as superoxide dismutase (Wang et al. 2010). The NADPH oxidases can be responsible for the $\mathrm{Cu}$-induced superoxide accumulation in WT Arabidopsis roots (Opdenakker et al. 2012). In the case of NO excess (noxl, gsnorl-3), $\mathrm{Cu}$ was not able to enhance superoxide level, probably because of the inactivation of NADPH oxidases by $S$-nitrosylation (Yun et al. 2011). As an effect of $\mathrm{Cu}, \mathrm{H}_{2} \mathrm{O}_{2}$ levels decreased as long as NO was present in excess, therefore, ROS detoxification could happen through the NO-dependent induction of expression of antioxidant genes such as glutathione peroxidase or glutathione transferase (Polverari et al. 2003). These enzymes were shown to be regulated also by NO-dependent $S$-nitrosylation (Lindermayr et al. 2005). Furthermore, in the case of NO deficiency, superoxide reduction was associated with $\mathrm{H}_{2} \mathrm{O}_{2}$ generation reflecting the possible SOD-dependent detoxification. The altered AsA metabolism and the consequently changed ROS content in vtc2-1,vtc2-3 and miox 4 mutants resulted in reduced NO levels, which suggests the impact of a strictly regulated ROS level on NO metabolism under stress-free conditions. On the basis of $\mathrm{Cu}$-induced nonsignificant alterations, it can be assumed that under $\mathrm{Cu}$ stress the impact of ROS on NO metabolism is negligible (Fig. 3d).

The results of the present study clearly show that Arabidopsis seedlings are able to uptake and accumulate $\mathrm{Cu}$ from the agar medium and translocate it into the shoot system. Its accumulation within the tissues fundamentally modifies microelement homeostasis of the seedlings, which can partly be responsible for the growth inhibition. Nitric oxide can intensify $\mathrm{Cu}$ sensitivity or can facilitate tolerance depending on the strength of the stress. The excess of ROS derived from ascorbic acid deficiency is associated with $\mathrm{Cu}$ sensitivity and vice versa. Moreover, NO mitigates $\mathrm{Cu}$ stress by regulating $\operatorname{ROS}\left(\mathrm{O}_{2}^{--}\right.$and $\left.\mathrm{H}_{2} \mathrm{O}_{2}\right)$ metabolism. Based on these findings, $\mathrm{Cu}$ stress tolerance is regulated by a fine-tuned NO/ROS balance in Arabidopsis.

Acknowledgments We thank Prof. Dr. G. F. E. Scherer (University of Hannover, Germany) for supplying the NR double mutant nialnia2 seeds and Dr. Christian Lindermayr (Helmholtz Zentrum München, Germany) for supplying the gsnorl-3 seeds. Noxl seeds were kindly provided by Professor Yikun He (Capital Normal University, Beijing, China). We also thank Dr. Laura Zsigmond (University of Szeged, Hungary) for the kind gift of $v t c 2-1, v t c 2-3$ and miox4 seeds, respectively. The authors wish to thank "Scientia Amabilis Foundation for Hungarian Plant Physiology" for the financial support. This work was supported by the Hungarian Scientific Research Fund (grant no. OTKA PD100504). We acknowledge HURO/0901/147/2.2.2 SZETISA1. Project for the ICP-MS instrumental background. This research was realized in the frames of TÁMOP 4.2.4. A/2-11-1-20120001 "National Excellence Program - Elaborating and operating an inland student and researcher personal support system". The project was subsidized by the European Union and co-financed by the European Social Fund.

\section{References}

Alford SR (2009) Molecular characterization of two myo-inositol oxygenases in Arabidopsis thaliana. Dissertation, Virginia Polytechnic Institute and State University 
Astier J, Kulik A, Koen E, Besson-Bard A, Bourque S, Jeandroz S, Lamotte O, Wendehenne D et al (2012) Protein $S$-nitrosylation: what's going on in plants? Free Rad Biol Med 53:1101-1110

Barth C, Gouzd ZA, Steele HA, Imperio RM et al (2010) A mutation in GDP-mannose pyrophosphorylase causes conditional hypersensitivity to ammonium, resulting in Arabidopsis root growth inhibition, altered ammonium metabolism, and hormone homeostasis. J Exp Bot 61:379-394

Burkhead JL, Reynolds KAG, Abdel-Ghany SE, Cohu CM, Pilon M et al (2009) Copper homeostasis. New Phytol 182:799-816

Conklin PL (2001) Recent advances in the role and biosynthesis of ascorbic acid in plants. Plant Cell Environ 24:383-394

Conklin PL, Saracco SA, Norris SR, Last RL et al (2000) Identification of ascorbic acid-deficient Arabidopsis thaliana mutants. Genetics 154:847-856

Cui XM, Zhang YK, Wu XB, Liu CS et al (2010) The investigation of the alleviated effect of copper toxicity by exogenous nitric oxide in tomato plants. Plant Soil Environ 56:274-281

Delledonne M, Zeier J, Marocco A, Lamb C et al (2001) Signal interactions between nitric oxide and reactive oxygen intermediates in the plant hypersensitive disease resistance response. Proc Natl Acad Sci 98:13454-13459

Dowdle J, Ishikawa T, Gatzek S, Rolinski S, Smirnoff N et al (2007) Two genes in Arabidopsis thaliana encoding GDP-L-galactose phosphorylase are required for ascorbate biosynthesis and seedling viability. Plant J 52:673-689

Epstein E, Bloom AJ (2005) Mineral Nutrition of Plants: Principles and Perspectives. Sinauer Associates, Inc., Sunderland

Feechan A, Kwon E, Yun B-W, Wang Y, Pallas JA, Loake GJ et al (2005) A central role for $S$-nitrosothiols in plant disease resistance. PNAS 102:8054-8059

Gouvêa CMCP, Souza JF, Magalhães CAN, Martins IS et al (1997) NO-releasing substances that induce growth elongation in maize root segments. Plant Growth Regul 21:183-187

He Y, Tang R-H, Hao Y (2004) Nitric oxide represses the Arabidopsis floral transition. Science 305:1968-1971

Hu K-D, Hu L-Y, Li Y-H, Zhang F-Q, Zhang H et al (2007) Protective roles of nitric oxide on germination and antioxidant metabolism in wheat seeds under copper stress. Plant Growth Regul 53:173-1831

Koppenol WH, Moreno JJ, Pryor WA, Ischiropoulos H, Beckman JS et al (1992) Peroxynitrite, a cloaked oxidant formed by nitric oxide and superoxide. Chem Res Toxicol 5:834-842

Kopyra M, Gwózdz EA (2003) Nitric oxide stimulates seed germination and counteracts the inhibitory effect of heavy metals and salinity on root growth of Lupinus luteus. Plant Physiol Biochem 41:1011-1017

Larkindale J, Hall JD, Knight MR, Vierling E et al (2005) Heat stress phenotypes of Arabidopsis mutants implicate multiple signaling pathways in the acquisition of thermotolerance. Plant Physiol 138:882-897

Lee U, Wie C, Fernandez BO, Feelisch M, Vierlinga E et al (2008) Modulation of nitrosative stress by $S$-nitrosoglutathione reductase is critical for thermotolerance and plant growth in Arabidopsis. Plant Cell 20:786-802

Lehotai N, Pető A, Bajkán Sz, Erdei L, Tari I, Kolbert Zs et al (2011) In vivo and in situ visualization of early physiological events induced by heavy metals in pea root meristem. Acta Physiol Plant 33:2199-2207

Lehotai N, Kolbert Zs, Pető A, Feigl G, Ördög A, Kumar D, Tari I, Erdei L et al (2012) Selenite-induced hormonal and signalling mechanisms during root growth of Arabidopsis thaliana L. J Exp Bot 63:5677-5687

Lequeux H, Hermans C, Lutts S, Verbruggen N et al (2010) Response to copper excess in Arabidopsis thaliana: impact on the root system architecture, hormone distribution, lignin accumulation and mineral profile. Plant Physiol Biochem 48:673-682

Leshem YY, Haramaty E (1996) The characterization and contrasting effects of the nitric oxide free radical in vegetative stress and senescence of Pisum sativum Linn. foliage. J Plant Physiol 148:258-263

Lidon FC, Henriques FS (1993) Effects of copper toxicity on growth and the uptake and translocation of metals in rice plants. J Plant Nutr 16:1449-1464

Lindermayr C, Saalbach G, Durner J (2005) Proteomic identification of $S$-nitrosylated proteins in Arabidopsis. Plant Physiol 137:921-930

Lorence A, Chevone BI, Mendes P, Nessler CL et al (2004) Myoinositol oxygenase offers a possible entry point into plant ascorbate biosynthesis. Plant Physiol 134:1200-1205

Lozano-Juste J, Léon J (2010) Enhanced abscisic acid-mediated responses in nialnia2noal-2 triple mutant impaired in NIA/NRand AtNOA1-dependent nitric oxide biosynthesis in Arabidopsis. Plant Physiol 152:891-903

Modolo LV, Augusto O, Almeida IMG, Pinto-Maglio CAF, Oliveira HC, Seligman K, Salgado I et al (2006) Decreased arginine and nitrite levels in nitrate reductase-deficient Arabidopsis thaliana plants impair nitric oxide synthesis and the hypersensitive response to Pseudomonas syringae. Plant Sci 171:34-40

Molassiotis A, Fotopoulos V (2011) Oxidative and nitrosative signaling in plants: two branches in the same tree? Plant Signal Behav 6:210-214

Müller-Moulé P, Golan T, Niyogi KK (2004) Ascorbate-deficient mutants of Arabidopsis grow in high light despite chronic photooxidative stress. Plant Physiol 134:1163-1172

Murphy A, Taiz L (1995) A new vertical mesh transfer technique for metal-tolerance studies in Arabidopsis ecotypic variation and copper-sensitive mutants. Plant Physiol 108:29-38

Negi S, Santisree P, Kharshiing EV, Sharma R et al (2010) Inhibition of the ubiquitin-proteasome pathway alters cellular levels of nitric oxide in tomato seedlings. Mol Plant 3:854-869

Opdenakker K, Remans T, Keunen E, Vangronsveld J, Cuypers A et al (2012) Exposure of Arabidopsis thaliana to $\mathrm{Cd}$ or $\mathrm{Cu}$ excess leads to oxidative stress mediated alterations in MAPKinase transcript levels. Environ Exp Bot 83:53-61

Pagnussat GC, Simontacchi M, Puntarulo S, Lamattina L et al (2002) Nitric oxide is required for root organogenesis. Plant Physiol 129:954-956

Pető A, Lehotai N, Lozano-Juste J, León J, Tari I, Erdei L, Kolbert Zs et al (2011) Involvement of nitric oxide and auxin in signal transduction of copper-induced morphological responses in Arabidopsis seedlings. Ann Bot 108:449-457

Polverari A, Molesini B, Pezzotti M, Buonaurio R, Marte M, Delledonne $\mathrm{M}$ et al (2003) Nitric oxide-mediated transcriptional changes in Arabidopsis thaliana. Mol Plant Microbe Interact 16:1094-1105

Potters G, Horemans N, Jansen MAK (2010) The cellular redox state in plant stress biology: a charging concept. Plant Physiol Biochem 48:292-300

Reichman SM (2002) The responses of plants to metal toxicity: a review focusing on copper, manganese and zinc. Australian Minerals \& Energy Environment foundation, p 22

Rustérucci C, Espunya MC, Díaz M, Chabannes M, Martínez MC et al (2007) S-nitrosoglutathione reductase affords protection against pathogens in Arabidopsis, both locally and systemically. Plant Physiol 143:1282-1292

Smirnoff N (2000) Ascorbate biosynthesis and function in photoprotection. Phil Trans R Soc Lond B 355:1455-1464

Taylor GJ, Foy CD (1985) Differential uptake and toxicity of ionic and chelated copper in Triticum aestivum. Can J Bot 63:1271-1275 
Tewari RK, Hahn E-J, Paek K-Y (2008) Modulation of copper toxicity-induced oxidative damage by nitric oxide supply in the adventitious roots of Panax ginseng. Plant Cell Rep 27:171-181

Vandelle E, Delledonne M (2011) Peroxynitrite formation and function in plants. Plant Sci 181:534-539

Wang L, Yang L, Yang F, Li X, Song Y, Wang X, Hu X et al (2010) Involvements of $\mathrm{H}_{2} \mathrm{O}_{2}$ and metallothionein in NO-mediated tomato tolerance to copper toxicity. J Plant Physiol 167: 1298-1306

Wilkinson JQ, Crawford NM (1993) Identification and characterization of a chlorate-resistant mutant of Arabidopsis thaliana with mutations in both nitrate reductase structural genes NIA1 and NIA2. Mol Gen Genet 239:289-297

Wintz H, Fox T, Wu YY, Feng V, Chen W, Chang HS, Zhu T, Vulpe $\mathrm{C}$ et al (2003) Expression profiles of Arabidopsis thaliana in mineral deficiencies reveal novel transporters involved in metal homeostasis. J Biol Chem 278:47644-47653

Xiong J, Fu G, Tao L, Zhu C et al (2010) Roles of nitric oxide in alleviating heavy metal toxicity in plants. Arch Biochem Biophys 497:13-20

Yruela I (2009) Copper in plants: acquisition, transport and interactions. Func Plant Biol 36:409-430

Yun B-W, Feechan A, Yin M, Saidi NBB, Le Bihan T, Yu M, Moore JW, Kang J-G, Kwon E, Spoel SH, Pallas JA, Loake GJ et al (2011) $S$-nitrosylation of NADPH oxidase regulates cell death in plant immunity. Nature 478:264-268

Zhao M-G, Chen L, Zhang L-L, Zhang W-H et al (2009) Nitric reductase-dependent nitric oxide production is involved in cold acclimation and freezing tolerance in Arabidopsis. Plant Physiol 151:755-767 